\title{
Do U.S. States' Socioeconomic and Policy Contexts Shape Adult Disability?
}

Jennifer Karas Montez $\mathrm{a}^{\mathrm{a}^{*}}$, Mark D. Hayward ${ }^{\mathrm{b}}$, Douglas A. Wolf ${ }^{\mathrm{c}}$

${ }^{a}$ Department of Sociology and Aging Studies Institute, 314 Lyman Hall, Syracuse University, Syracuse NY 13244, USA. Email: jmontez@ maxwell.syr.edu, Phone: +1 315-443-9064, Fax: +1 315-443-9098

${ }^{\mathrm{b}}$ Population Research Center, 1800 Main, University of Texas at Austin, Austin TX 78705, USA. Email: mhayward@ prc.utexas.edu

${ }^{c}$ Department of Public Administration and International Affairs, and Aging Studies Institute, 314 Lyman Hall, Syracuse University, Syracuse NY 13244, USA. Email: dawolf@ maxwell.syr.edu

*Corresponding author.

\section{Abstract}

Growing disparities in adult mortality across U.S. states point to the importance of assessing disparities in other domains of health. Here, we estimate state-level differences in disability, and draw on the WHO socio-ecological framework to assess the role of ecological factors in explaining these differences. Our study is based on data from 5.5 million adults aged 25-94 years in the 2010-2014 waves of the American Community Survey. Disability is defined as difficulty with mobility, independent living, self-care, vision, hearing, or cognition. We first provide estimates of age-standardized and age-specific disability prevalence by state. We then estimate multilevel models to assess how states' socioeconomic and policy contexts shape the probability of having a disability. Age-standardized disability prevalence differs markedly by state, from $12.9 \%$ in North Dakota and Minnesota to $23.5 \%$ in West Virginia. Disability was lower in states with stronger economic output, more income equality, longer histories of tax credits for lowincome workers, and higher cigarette taxes (for middle-age women), net of individuals' socio- 
demographic characteristics. States' socioeconomic and policy contexts appear particularly important for older adults. Findings underscore the importance of socio-ecological influences on disability.

Keywords: United States; disability; health; social determinants; states 
The United States has fallen precipitously in international rankings of life expectancy in recent decades, both in terms of life expectancy at birth and at age 50 (National Research Council, 2011). The fall partly reflects the large and growing differences in life expectancy across U.S. states (Wilmoth et al., 2011). While differences in longevity between states have been the focus of recent research (Montez et al., 2016; Patel et al., 2014; Tencza et al., 2014; Wilmoth et al., 2011), much less is known about cross-state differences in health. Do they mirror differences in life expectancy? Do they mainly reflect states' population characteristics (e.g., residents' educational attainment) or states' socioeconomic and policy environments? And, given evidence that the magnitude of mortality differences across states is dissimilar for women and men and across age groups (Wilmoth et al., 2011), are health differences also dissimilar across gender and age groups?

This study begins to address gaps in our understanding of cross-state differences in health by examining adult disability given its salience for independent living and healthcare costs. The central questions are: (1) to what extent do states differ in their prevalence of disability, (2) do these differences vary by gender and age, and (3) do states' socioeconomic and policy contexts shape disability status, net of individuals' sociodemographic characteristics? Our study extends prior work in several ways: (1) it is grounded in the socio-ecological framework proposed by the World Health Organization (WHO); (2) it utilizes a multilevel approach to estimate disability from individual-level characteristics and state-level contexts, while accounting for the clustering of individuals within state and local areas; (3) it examines gender-age subgroups; and (4) it uses a large dataset on over 5.5 million adults across all state and local areas. The results shed light on the importance of states' contexts for adult disability status. 


\section{Prior Research}

As Lin (2000) observed over a decade ago, comparatively few studies of geographic disparities in U.S. health and mortality have examined health, and even fewer have investigated the policy contexts that contribute to those disparities - a critique that holds true today. This comparative lack of evidence was again made apparent in a recent review of studies examining contextual factors and disability (Philibert et al., 2015). It located just 16 U.S. studies published between 1998 and 2014 that met the basic search parameters of the review.

Most U.S. studies have focused on documenting geographic differences in later-life disability. Further, most have examined large geographic areas such as regions and divisions, which are not policy-making units but rather are delineated by the U.S. Census Bureau for the presentation of census data. In general, these studies find that geographic differences in disability are large and cannot be entirely accounted for by population characteristics. Lin (2000) used the 1990 Census to examine differences across 11 regions in the prevalence of disability among adults aged 65 years and older. The differences were stark and persisted net of individuals' demographic and socioeconomic characteristics. Using the same sample, Lin and Zimmer (2002) did a simulation study and concluded that raising education levels of the population would lower disability rates, but would not erase the effects of contextual factors.

One particularly interesting conclusion of the two studies just mentioned (see also Kington et al., 1998) is that adults seem to carry with them some residual risk of disability from their area of birth. In particular, being born in a Southern state appears to leave a lasting imprint among out-migrants. These conclusions resonate with the mounting evidence on the enduring consequences of early-life conditions on later-life health and mortality (Montez \& Hayward, 2011). They also imply that geographic exposures throughout the life course may shape disability status. For these reasons, studies aiming to understand how geographic exposures 
shape adult disability typically focus on the majority of the population who were born in the state in which they reside at the time of survey ("stayers") and occasionally contrast them against "movers". Consistent with these studies, we focus on stayers in most of our analyses.

While the studies mentioned above did not assess gender differences in their multivariate analyses, Porrell and Miltiades (2002) did and found intriguing results. Using data on adults aged 65 years and older in the 1992-1995 Medicare Current Beneficiary Survey, the authors assessed whether individual characteristics (demographics, socioeconomics, lifestyles, and chronic conditions) and county characteristics (socioeconomics and medical care) explained disparities in disability across seven regions. Interestingly, individual characteristics explained more of the disparities among men than women, while county characteristics (mainly socioeconomic in nature) explained more among women than men. Several subsequent studies have similarly found that contextual factors have a stronger association with women's than men's health and longevity (see Montez et al., 2016).

The few studies that have examined disability-related outcomes across states report striking disparities. One recent study documented large disparities in the Health and Activities Limitation Index across states among adults 65 years and older (Kachan et al., 2014). Two other studies used data on adults 25 and older in the 2003 or 2006 American Community Surveys to examine whether states' income inequality helps explain the large interstate variation in disability (Fuller-Thomson \& Gadalla, 2008; Gadalla \& Fuller-Thomson, 2008). Greater income inequality was associated with higher disability prevalence, net of individuals' income.

Our review illustrates that few studies have investigated state-level disparities in disability or the state-level policies and mutable contextual factors, such as a state's economy, that contribute to the disparities. Our study begins to address this gap by drawing on the socioecological framework proposed by WHO (Solar \& Irwin, 2010) and examining specific state 
contexts as potential explanations. Our review also revealed a lack of attention to gender and age differences. We investigate these potentially heterogeneous effects as they may provide clues about mechanisms and the populations at greatest risk. For instance, state policies and contexts may be more relevant for women given that they are more likely than men to be poor, raising children, caring for elders, and interacting with the health care system; they may also be more relevant during certain life course stages. In addition, most studies have not employed multilevel modeling approaches. This is an important omission because geographic inequalities in disability reflect an intrinsically multilevel phenomenon (Subramanian et al., 2001).

\section{Conceptual Framework}

The socio-ecological framework proposed by the WHO's Commission on Social Determinants of Health (Solar \& Irwin, 2010) organizes the complex processes that generate inequalities in population health into three main layers. Overarching socioeconomic and policy contexts, the top layer, create stratification systems based on socioeconomic resources, gender, and race and ethnicity (middle layer). These systems, in turn, expose individuals to proximal risks and resources for health, such as health behaviors (the bottom layer). The framework refers to the top two layers as structural determinants, and the bottom layer as intermediary determinants, to underscore the causal priority of the former. In this study we focus on structural determinants.

The WHO framework incorporates aspects from previous frameworks (especially from Diderichsen and colleagues (2001)) but emphasizes the role of socioeconomic and policy contexts in stratifying power and social position. Like previous frameworks, it recognizes that individuals' socioeconomic resources are a key social determinant of health. However, it emphasizes that the distribution of those resources, as well as their importance for avoiding health risks and garnering health advantages, is heavily shaped by overarching contexts. As 
noted by WHO these contexts have been "seriously understudied" in the literature on the social determinants of health (for an exception see Navarro, 2004) despite the fact that they profoundly impact people's capacity to live healthy lives.

Although the WHO framework was not developed for a specific health-related outcome, it is conceptually consistent with the Disablement Process, one of the most widely-used sociomedical frameworks (Verbrugge \& Jette, 1994). Like the WHO framework, the Disablement Process posits that disability results from the confluence of "extra-individual" factors on the one hand and "intra-individual" factors, such as education and a sense of control, on the other. Both assume that the primary causal pathway is one in which extra-individual factors impinge on individuals' lives. Yet, both recognize that the causal pathways are complex, inextricably linked, and contain feedback loops. Our study does not disentangle these intractably complex causal pathways. Rather, our aim is to understand the extent to which a focused set of state contexts predicts disability, net of adults' sociodemographic characteristics.

\section{Five Measures of States' Socioeconomic and Policy Contexts}

The WHO framework organizes the myriad extra-individual factors that shape population health into seven categories - governance, macroeconomic policies, social policies, public policies, culture and societal values, social capital or cohesion (hereafter, "social capital"), and the health system — referring to the first five as "socioeconomic and political contexts". We adapt the seven categories and their labels to be more meaningful for an investigation of disability across U.S. states. They include macroeconomic conditions, social policies, public health policies, social capital, and the health care system; we refer to them collectively as socioeconomic and policy contexts. 
As the WHO framework is conceptual, it does not provide concrete guidance on how to operationalize it. Consequently, we developed explicit criteria to systematically select state-level measures that span the five categories (the criteria are described in the methods section). Our selection process identified one state-level measure within each category. While each measure is an important representation of the category, it does not wholly capture the category. The selected state-level measures contain the two most widely-studied measures (economic vibrancy, income inequality) along with three policy measures (Earned Income Tax Credit, cigarette sales tax, Medicaid). Next, we describe the five measures according to the WHO category they best reflect. The first category, macroeconomic conditions, refers to the vibrancy (or lack thereof) of a state's economy. These conditions are typically assessed with aggregate indicators such as gross domestic product, inflation, growth rates, and unemployment. We focus on the gross state product per capita (GSPPC), which captures the market value of goods and services produced in a state. States with higher GSPPC tend to have more of its population engaged in the labor force and have more money to spend on infrastructure, social services, public education system, and so on, all of which can enhance population health.

The social policies category is largely comprised of wage, housing, land, and poverty policies, and policies affecting access to material resources, such as labor policies. Our study focuses on the largest anti-poverty program in the United States, the Earned Income Tax Credit (EITC), which distributes about the same amount of payments as two other major anti-poverty programs, Temporary Assistance for Needy Families and the Supplemental Nutrition Assistance Program, combined (Evans \& Garthwaite, 2014). Created in 1975, EITC is a refundable tax credit for low-income working adults, with greater benefits for parents with minor children. As of January 2016, 26 states and D.C. supplemented the federal EITC. In addition to improving economic outcomes, EITC may improve health. Much of this evidence is derived from studies of 
women, given that they are more likely than men to be poor and raising children. Among women, EITC has been found to reduce smoking and increase birth weights (Strully et al., 2010), and elevate self-reported health and reduce risky biomarkers (Evans \& Garthwaite, 2014).

The public health policy category captures policies that more directly affect health such as tobacco regulations. For several reasons, our study focuses on tobacco sales taxes. First, cigarette smoking is a major risk factor for disability (Stuck et al., 1999). One of the most effective tools governments use to deter smoking is tobacco sales taxes (WHO, 2010); however, that tax differs markedly across states. In addition, the effect of this taxation differs across population subgroups. Persons with incomes at or below the median are more than four times as responsive to increases in cigarette prices as people with incomes above the median (Farrelly et al., 2001), and women are nearly twice as responsive as men (Stehr, 2007). Therefore, states with higher tobacco taxes may have lower disability rates, and this may be most evident for women.

The fourth category, social capital, captures social and economic integration. This category occupies a tenuous position in the WHO framework, which asserts that focusing on social capital risks encouraging depoliticized approaches to population health. Moreover, some scholars assert that we know much less about how to build social capital than we do about how to destroy it through various social and economic factors, most notably income inequality (Kawachi et al., 1997). Income inequality is thought to erode social capital by creating social conflict, engendering mistrust, and widening the social distance between the haves and have-nots (Kawachi \& Kennedy, 1999; Kawachi et al., 1997), which can compromise population health. In fact, individuals living in states with higher income inequality are more likely to have a self-care disability (Fuller-Thomson \& Gadalla, 2008), lower self-rated health (Subramanian et al., 2001), and higher mortality (e.g., Kawachi et al., 1997). Because there are no well-established policy levers for improving social capital, because the concepts can be perceived by policymakers to be 
outside the realm of political action, and because income inequality is considered to be a major determinant of social capital, we include a measure of income inequality for this category.

The final category includes the health care system. We focus on Medicaid, the largest source of public health insurance, currently covering roughly 70 million Americans (Kaiser Family Foundation, 2015). Prior to the recent expansion associated with the Affordable Care Act, Medicaid covered specific categories of low-income individuals including children, pregnant women, parents of dependent children, individuals with disabilities, and seniors (including more than $20 \%$ of "dually eligible" Medicare beneficiaries) (Kaiser Family Foundation, 2015). Medicaid is jointly financed by the Federal and state governments, with the Federal share of programmatic expenditures ranging from $50 \%$ to over $70 \%$ at present. Subject to meeting Federal minimum requirements, states design and administer their own Medicaid programs, choosing among a number of program options and eligibility criteria. This has led to substantial variation across states in eligibility requirements, covered services, quality of care, and reimbursement (Ramírez de Arellano \& Wolfe, 2007). To the extent that Medicaid improves health (Kaiser Family Foundation, 2013), state-level differences in the program may contribute to state-level disparities in disability.

\footnotetext{
Aims

Using a nationally-representative sample of over 5.5 million adults in the American Community Survey, this study examines the magnitude of, and potential explanations for, disparities in disability across states. The extensive size and geographic detail of the survey make it possible to address fundamental questions about these disparities that have been hindered by data availability. It is possible to examine disparities across the adult life course and for gender-age subgroups. It is also possible to isolate the contribution of individual versus state characteristics
} 
to the disparities, while accounting for local area variation in disability. Our study is guided by three questions:

(1) To what extent does adult disability prevalence vary across U.S. states? We estimate agestandardized and age-specific prevalence for each state. We expect that the prevalence of disability differs markedly across states, and that younger adults in "unhealthy" states experience levels of disability similar to adults who are a decade or two older in "healthy" states.

(2) How does the state variation in disability differ by age, gender, and exposure to a state? We expect cross-state variation in disability to be greater among older than younger adults, and among stayers than movers, given that older adults and stayers have lived longer in (i.e., had greater "exposure" to) their state of residence.

(3) Is state variation in disability associated with differences in states' socioeconomic and policy contexts? Do these patterns differ between men and women? Do they differ between younger, midlife, and older adults?

\section{METHODS}

\section{Data}

The public-use 2010-2014 American Community Survey (ACS) is a nationally representative sample of 15,552,114 individuals. The U.S. Census Bureau provides 1- and 5- year ACS files for public use. Each 5-year file combines annual cross-sectional waves with sample weights adjusted to make it nationally representative (calendar years are masked). The 2010-2014 ACS is the most recent 5-year file. It contains the necessary sample size and geographic detail for our study.

The ACS identifies different types of local geographic units such as census tracts, counties, and Public Use Microdata Areas (PUMAs). We use PUMAs because they are the 
smallest level of geography in the data. Covering the entire nation, the 2,378 PUMAs consist of one or more contiguous counties or census tracts within a state so that each contains at least 100,000 persons. We hereafter refer to PUMAs as "local areas." Lastly, we collected data on state-level contexts from external sources, as explained below, and merged it into the ACS.

\section{Analytic Sample}

We define three separate analytic samples and estimate the age-standardized probability of disability for each sample by state. The first sample contains the 10,751,690 adults 25-94 years of age residing in the 50 states. We set the lower age limit at age 25 years because our aims concern adult disability and because one of the individual covariates is educational attainment. We set the upper limit at 94 years because the ACS top-codes ages at 99 years; and including ages 25-94 years conveniently provides seven 10-year age groups. The second sample contains the 9,226,759 of these adults who were U.S-born. The third sample contains the 5,571,075 $(60.4 \%)$ adults born in their state of residence. We use the third sample for most analyses to help isolate the importance of states by identifying adults with the longest exposure to their state of residence. Like others who have used this approach (e.g., Gadalla \& Fuller-Thomson, 2008; Lin \& Zimmer, 2002) we recognize it is not a perfect measure of exposure. Moreover, differing patterns of out- and return-migration propensities across states means that lifetime patterns of exposure will differ by state and by state-age group combinations. Nonetheless, adults in the third sample will, on average, have lived longer in the state than have migrants.

\section{Disability}

Although "health" and "disability" are distinct concepts, they share many features; chronic health conditions and their functional manifestations are strongly associated with having a 
disability (Freedman et al., 2014). The ACS asked six disability-related questions. It asked if the individual was: (1) deaf or had serious difficulty hearing, (2) blind or had serious difficulty seeing even when wearing glasses; and whether, because of a physical, mental, or emotional condition, the individual had difficulty (3) concentrating, remembering, or making decisions, (4) walking or climbing stairs, (5) dressing or bathing, and (6) doing errands alone such as visiting a doctor's office or shopping. We use a binary indicator of whether the individual responded affirmatively to at least one of the six questions. It is a more global measure than a single item and it provides a sufficient number of affirmative responses for young adults and our multilevel models. While it is not strictly a measure of disability, we refer to it as such for ease. In supplementary analyses, we replicated the models for each of the six disability-related measures.

\section{Individual Characteristics}

In addition to age, we include race/ethnicity and educational attainment as "fundamental causes" (Phelan \& Link, 2005) of adult disability. Age ranges from 25 to 94 years. Race/ethnicity is a four-category variable indicating non-Hispanic white (the reference category), non-Hispanic black, non-Hispanic other, and Hispanic. We focus on educational attainment as the main marker of socioeconomic resources (SES). Education is causally prior to other socioeconomic resources, such as income and occupation; it is the most stable across the life course; and it is the least affected by declining health (Mirowsky \& Ross, 2003). In addition to endogeneity concerns about using employment and income as predictors of disability, these SES measures are less meaningful for older adults. Education is included as years of schooling ranging from 0 to $21+$ years. In supplementary analyses we examined a three-category measure of education; however, the results were substantively identical. 


\section{State Characteristics}

We used the WHO framework as a guiding principle to select state-level measures that span the five categories of interest. One challenge in using this conceptual framework is that it does not provide concrete guidance on how to select measures of each category. Moreover, many measures do not fit exclusively within one category. For instance, income inequality might fit within macroeconomic conditions, social policies, and social capital. We addressed this challenge by consulting existing studies and developing selection criteria. First, we consulted a recent U.S. study that conducted a factor analysis of 21 state-level measures (Montez et al., 2016). It identified five factors: economic environment, sociopolitical orientation, social cohesion, tobacco environment, and physical infrastructure. For example, the social cohesion factor contained state-level measures of income inequality, social capital, crime, and unemployment. Because the first four latent factors from Montez et al (2016) map onto the WHO categories remarkably well, we assigned the state-level measures within those factors to their respective WHO category. We then added measures of the fifth WHO category, the health care system.

We then developed criteria to select one measure for each category. We preferred this approach over using multiple measures (because this creates multi-collinearity) or latent factor scores (because this masks information about specific measures). Our selection criteria sought measures that are: strongly correlated with states' disability prevalence; are well-established as having an independent association with population health and mortality; have direct policy implications; are particularly salient for socioeconomically-disadvantaged adults (because these adults have the fewest personal resources for health they may be most affected by resources provided by states, a conjecture in line with Chetty et al.(2016)); and are more likely to be a 
cause than a consequence of states' disability prevalence. Appendix Table S1 describes the selection process in detail and lists all variables considered for the analysis.

We include the gross state product per capita (data source: U.S. Bureau of Economic Analysis, n.d.), a measure of the states' macroeconomic conditions. We include the state sales tax on a pack of cigarettes (data source: CDC, n.d.), a measure of public health policies. We also include the state Gini coefficient of income inequality (data source: Noss, 2011; U.S. Census Bureau, n.d.); while it is not a direct measure of social capital, it is a strong correlate. For these three measures we include their average value across 1990, 2000, and 2010 to capture an extended period of exposure prior to the 2010-2014 ACS. Fourth, we include the number of years before 2010 that the state had offered a supplement to the federal EITC (data source: TCWF, n.d.), a measure of social policies. Lastly, we use an overall score of the generosity of the states' Medicaid program, a measure of access to health care for low-income and disabled persons. The overall scores were developed by the Public Health Citizen Research Group in 1987 and 2007 using Kaiser Family Foundation data (Erdman \& Wolfe, 1987; Ramírez de Arellano \& Wolfe, 2007). For both years the overall scores are a weighted average of separate scores for the Medicaid programs' eligibility, scope of services, quality of care, and reimbursement (and also provider availability in 1987). We include the average of the 1987 and 2007 overall scores, where higher scores reflect more generous programs. All state-level measures are standardized to have mean $=0$ and standard deviation $=1$.

The five state-level measures are shown in Table 1 . It contains 10 of the 50 states for parsimony; all states are available in Appendix Table S2. The states are sorted in ascending order of their age-standardized disability prevalence. Compared to the bottom 5 states, the top 5 have, on average, higher GSPPC, longer histories of offering a supplemental EITC, lower income inequality, higher sales tax on cigarettes, and higher Medicaid program scores. 


\section{Analytic Strategy}

[Table 1 about here]

To address aim 1, for each state we estimate the age-specific disability prevalence within seven 10-year age groups (ages $25-34,35-44, \ldots, 85-94$ years). We also estimate the age-standardized disability prevalence (ASDP). By removing age composition differences between states, the ASDP allows comparisons of overall disability prevalence between states. For each state the ASDP is estimated by multiplying the disability prevalence for each age group by the 2010 U.S. population size for each age group, then dividing the sum of those seven numbers by the total U.S. population aged $25-94$ years. We chose the 2010 population as the standard so that we could use Census data overlapping with the 2010-2014 ACS. To address aim 2 we use variance comparison tests to contrast the cross-state variation in disability between subgroups.

For aim 3 we estimate a series of multilevel random effects logit models. The models account for the three-level hierarchical structure of the data, with individuals (level 1) nested within local areas (level 2) nested within states (level 3). The model without covariates is shown below. Subscript " $i$ " identifies individuals, “ $j$ ” identifies states, and " $k$ " identifies local areas.

$$
\ln \left(p_{i j k} /\left(1-p_{i j k}\right)\right)=\beta_{0}+v_{j}+u_{j k} \quad \text { where } v_{j} \sim N\left(0, \sigma_{v}^{2}\right) \text { and } u_{j k} \sim N\left(0, \sigma_{u}^{2}\right)
$$

In the model, $\beta_{0}$ is the average log-odds of disability among adults in the sample, $v_{j}$ is the effect of state " $j$ ", and $u_{j k}$ is the effect of local area " $k$ ". The quantities $v_{j}$ and $u_{j k}$ are assumed to be normally distributed with constant variances, $\sigma_{v}^{2}$ and $\sigma_{u}^{2}$. They are interpreted as the unexplained variation in disability at the state and local levels, respectively, net of variables in the model.

We progressively add the individual and state variables and assess their contribution to the variation in adult disability across states by monitoring the attenuation of the state-level variance, $\sigma_{v}^{2}$. All models are stratified by gender. Model 1 includes age and race/ethnicity. Model 2 adds educational attainment to assess how SES differences contribute to cross-state variation in disability. Lastly, Model 3 adds the state-level measures to assess their contribution to the 
variation. All models are estimated with xtmelogit in Stata MP 14.1 using an unstructured covariance matrix for the random effects. The models include years 2012-2014 because only for these years are the PUMA boundaries consistently defined.

\section{RESULTS}

\section{To what extent does adult disability prevalence vary across U.S. states?}

The left side of Table 2 shows the ASDP within each state. The first column contains the ASDP for all adults and the second column for U.S.-born adults. For example, if the age distribution of U.S.-born adults aged 25-94 years in California and South Dakota were the same as the 2010 U.S. distribution, roughly $15.2 \%$ of adults in both states would have a disability. The third column contains the ASDP for adults born in their state of residence (the table is sorted by this column). It varies markedly across states, ranging from $12.9 \%$ in North Dakota and Minnesota to $23.5 \%$ in West Virginia, an almost two-fold difference. The geographic pattern is illustrated in Figure 1, with several high disability states in the South and Southwest, and several low disability states in the upper plains, upper Midwest, and Northeast.

[Table 2 and Figure 1 about here]

The right side of Table 2 shows disability by 10 -year age groups. To illustrate the agespecific patterns, the cells are shaded so that each $10 \%$ increment in prevalence is a darker shade until reaching 50\%. Disparities across states are apparent even among adults aged 25-34 years, ranging from $4.1 \%$ in North Dakota to $10.5 \%$ in West Virginia. Within most age groups the disparities are large in both relative and absolute terms. For example, disability prevalence among adults aged 65-74 years ranges from $20.7 \%$ in Minnesota to $44.0 \%$ in Alaska. The patterns concur with our expectation that younger adults in the "unhealthiest" states experience levels of disability similar to adults a decade or two older in the "healthiest" states. For instance, 
adults aged 25-34 years in Kentucky and Maine experience disability levels similar to adults aged 35-44 in Virginia and Michigan, and to adults aged 45-54 years in North Dakota and Wisconsin. Also alarming, in many states $20-30 \%$ of working-age adults report a disability.

As noted before, Table 2 shows the 50 states in ascending order of ASDP for adults born in their state of residence. It is also possible to rank states separately by each of the seven agespecific disability prevalences. When we do so (in Appendix Table S3), interesting differences across age groups and states are revealed. For example, only Minnesota is among the top five (i.e., least disabled) in all seven age categories, while only Iowa is consistently among the top 10. In contrast, three states_Alabama, Kentucky, and Mississippi—are ranked among the bottom (i.e., most disabled) 10 states across all seven age groups. Several states exhibit striking differences by age in their relative disability-prevalence measures. Oregon, for example, seems to do well at the oldest ages (ranked $7^{\text {th }}$ in the 85-94 year age group) but badly among the young (ranked $43^{\text {rd }}$ and $44^{\text {th }}$, respectively, in the 25-34 and 35-44 year age groups). Alaska's pattern is just the opposite: it is ranked $9^{\text {th }}$ and $11^{\text {th }}$, respectively, in the 25-34 and 35-44 year age groups, but last for ages 65-84 years. These age-specific patterns suggest intriguing possibilities for our multilevel models: state contexts may have age-specific consequences.

\section{How does the state variation in disability differ by age, gender, and exposure to state?}

To compare the state variation in ASDP across age we must account for the fact that disability rises with age. Thus, we compare the coefficient of variation $\left(\mathrm{CV}_{\mathrm{ASDP}}=\sigma_{\mathrm{ASDP}} / \mu_{\mathrm{ASDP}}\right)$. The CV of ASDP across states for each age group is 0.187 (ages 25-34), 0.206 (ages 35-44), 0.214 (ages 4554), 0.213 (ages 55-64), 0.183 (ages 65-74), 0.136 (ages 75-84), and 0.051 (ages 85-94). Contrary to expectation, variation in ASDP across states does not increase monotonically with age. Instead, it increases until around 65 years of age and then shrinks, perhaps due to mortality 
selection or to federal entitlement programs such as Medicare and Social Security that reduce inequalities in income and access to medical care.

Surprisingly, we find no significant gender difference in the variance of ASDP across states $(F$-statistic $=0.94, p=0.84)$. Table 3 contains the gender-specific range, interquartile range, and standard deviation of ASDP across states. Among adults born in their state of residence (labeled as "state of residence (stayers)" in the table), the standard deviation of ASDP across states is 2.83 for women and 2.91 for men. Not only is the variation similar for women and men, there is a strong correlation in their ASDP across states ( $r=0.94$, Appendix Table S4).

[Table 3 about here]

Consistent with our hypothesis, the state variation in ASDP is largest among adults born in their state of residence, among both male and female residents. Table 3 shows the variation for these adults and four other exposure groups. Note that some groups are subsets of others. Among women the variation in ASDP across states is significantly greater among stayers $(\sigma=2.83)$ than in-migrants $(\sigma=2.23$, one-sided $p=0.050)$ and out-migrants $(\sigma=2.21$, one-sided $p=0.045)$. We reach the same conclusions for men. Similar to other studies (e.g., Lin, 2000), for comparative purposes the table also includes two groups where ASDP is estimated by state of birth.

So far, the descriptive analyses have generated several important findings. Disparities in ASDP across U.S. states are large in both relative and absolute terms. Disparities in age-specific rates are even more striking. As a result, adults in some states reach certain levels of disability one or two decades before adults in other states. The patterns are similar for women and men, and for non-Hispanic whites (Appendix Table S4). They are also consistent our expectation that state contexts may be most salient for adults with the longest exposure to them. But, which contexts are important? To address this question, we turn to our third aim. 


\section{Does the state variation reflect differences in states' socioeconomic and policy contexts?}

The results for women in Table 4 contain odds ratios (OR) of having a disability estimated from a series of multilevel logistic regression models. The first model for each age group is a baseline model containing women's age and race/ethnicity, plus random effects for state and local areas. The first model for young women indicates that, net of age and race/ethnicity, the unexplained variation in young women's disability that is attributable to state contexts is $\sigma_{v}^{2}=0.040$ and to local contexts is $\sigma_{u}^{2}=0.101$. That is, $28 \%[0.040 /(0.040+0.101)]$ of this contextual variation in disability is from the state level. This percentage rises with age, to $35 \%[0.058 /(0.058+0.107)]$ among middle-age women and 51\% [0.036/(0.036+0.034)] among older women. Accounting for women's education in model 2 reduces the absolute size of the unexplained contextual variation attributable to states (e.g., $\sigma_{v}^{2}$ for young women declined from 0.040 to 0.027 ) and local areas (e.g., $\sigma_{u}^{2}$ for young women declined from 0.101 to 0.059 ), a pattern seen across age groups. Nevertheless, net of women's age, race/ethnicity, and education, states still contribute much of the contextual variation: $31 \%, 39 \%$, and $54 \%$ across age groups. State contexts appear to be an important and independent factor for women's disability status.

\section{[Tables 4 and 5 about here]}

The third model in each age group adds the five state characteristics. These characteristics help explain the variation in women's disability across states. Net of women's socio-demographic characteristics, the five state characteristics account for $26 \%, 65 \%$, and $61 \%$ of the state variation in women's disability for the three age groups, respectively (e.g., $65 \%=$ 100(0.043-0.015)/0.043 for middle-age women). States' GSPPC, income inequality, and supplemental EITC (for older women) are particularly important. For example, net of women's age, race/ethnicity, and education, each standard deviation increase in GSPPC is associated with a $6 \%$ reduction $(\mathrm{OR}=0.94, p<0.01)$ in the odds of disability among middle-age women. Each 
standard deviation increase in the Gini coefficient is associated with a $10 \%$ increase $(\mathrm{OR}=1.10$, $p<0.001)$ in middle-age women's odds of disability. In addition, living in a state with a longer history of supplemental EITC was beneficial for older women $(\mathrm{OR}=0.96, p<0.05)$, while higher tobacco taxes were marginally beneficial for middle-age women $(\mathrm{OR}=0.96, p<0.10)$.

Table 4 also provides model fit indices. Within each age group, the Akaike Information Criterion is smallest for the model with state-level characteristics, indicating it is the best fitting model. In addition, the Likelihood Ratio Test for each model indicates that each fits the data better than an individual-level model. These conclusions about model fit also hold for men.

The results for men are shown in Table 5. State contexts also appear to be an important source of inequality in men's disability. Net of men's age and race/ethnicity, 20\%, 28\%, and $49 \%$ of the unexplained contextual variation in disability among young, middle-age, and older men, respectively, was at the state level. This variation is partly accounted for by state characteristics. Net of men's age, race/ethnicity, and education, the state characteristics account for $35 \%, 60 \%$, and $50 \%$ of the state variation in disability among younger, middle, and older men, respectively. Similar to the results for women, economic conditions as measured by GSPPC are a strong predictor of men's disability across age groups. Income inequality is a strong predictor for young and middle-age men (as it was for women), but it does not predict disability among older men (although it did for women). A long history of offering supplemental EITC was beneficial for older men as it was for older women: for every standard deviation increase in the number of years EITC had been available, the odds of disability decreased by $4 \%(p<0.10$ for men, $p<0.05$ for women). Also interesting, while high tobacco taxes predicted lower odds of disability for middle-age women they were not associated with disability for men. In sum, the five state-level characteristics explained a substantial portion of the variation in women's and men's disability across states, but some variation remains even after accounting for these factors. 


\section{Supplementary Analyses}

We conducted supplementary analyses, which provide additional support for our results. First, we assessed whether it would have been sufficient to estimate a two-level model of individuals within states, or a two-level model of individuals within local areas. We replicated Tables 4 and 5 using both of these two-level models and conducted a series of Likelihood Ratio Tests (Leckie, 2013). The three-level model was clearly preferred ( $p<0.0001$ for all comparisons).

We also tested whether the two gender differences suggested by the models in Tables 4 and 5 were statistically significant. In separate models that combined men and women and included a gender-by-income-inequality interaction, the interaction was significant across all age groups: the association between inequality and disability was stronger for women. We then estimated another model with a gender-by- tobacco-tax interaction. Tobacco taxes were significantly more protective for middle-age women than men.

We conducted several additional tests on the state-level variables. In preliminary analyses we confirmed that our results were not adversely affected by correlations between the state-level variables (pairwise correlations ranged from -0.11 to 0.64 ). The size and significance of statelevel coefficients were similar whether included separately or jointly in the models. We also examined an alternative specification of EITC. Because EITC is a benefit for working adults, it may seem odd that it was a significant predictor of disability only for adults aged 65 years and older. Recall, our EITC measure is the number of years that the state had offered a supplemental EITC prior to 2010. Our finding makes sense if it is cumulative, rather than contemporaneous, exposure to EITC that it is important. One way to assess the plausibility of this interpretation is to re-estimate the models using a binary measure of EITC, where 1=state currently offers a supplemental EITC, and $0=$ it does not. A non-significant $(p>0.10)$ EITC coefficient across all age groups would support our interpretation. This is precisely what we found in these models. 
While three state variables (EITC, cigarette taxes, Medicaid) are inherently state-level characteristics, two variables (income inequality and GSPPC) may vary across local areas as well. We assessed the robustness of the results to accounting for local income inequality (a local Gini coefficient can be estimated using the ACS, but there is no comparable local GSPPC). In ancillary analyses we added local income inequality to model 3 in each gender-age group. For women, the state income inequality OR was robust. It was less robust among men: the state OR was no longer significant for ages 25-44 years, became marginally significant for ages 45-64 years, and remained non-significant for older men.

Lastly, we replicated the models for each of the six disability-related measures (Appendix Tables S5 and S6). The findings generally corroborate the main analysis, suggesting that states' contexts have far reaching consequences across multiple disability-related domains. The few unexpected findings (e.g., young women in states with more generous Medicaid programs were significantly less likely to report vision problems) should be interpreted cautiously. The large number of statistical tests across these 108 models elevates the chances of type I error. In addition, the very small prevalence of disability in some models affects the coefficients' size and standard errors, and likely contributes to the convergence problems we encountered with several models. Nonetheless, further study of specific disability measures may be warranted.

\section{DISCUSSION}

Several recent studies have examined disparities in adult mortality across U.S. states, while less attention has been given to disparities in morbidity and disability. This study begins to address that gap. It illustrates the importance of states' socioeconomic and policy contexts on disability.

Five findings are noteworthy. First, states matter. A substantial fraction of the variation in adult disability that was attributable to "extra-individual" factors was at the state level. Among 
young adults this fraction was one-fourth and among middle-age and older adults it was one-half. In addition, our multilevel models that included individuals, local areas, and states fit the data significantly better than supplementary models that only included individuals and local areas.

Second, disparities in adult disability across U.S. states are substantial. They are evident even among adults in their 20s and most pronounced among adults in midlife, a time when many are trying to raise families, work outside the home, care for aging parents, and live independently. In many states as much as 20-30\% of working-age adults report a disability, which does not bode well for these states' economic growth and health care costs. There seems to be something particularly disadvantageous about living in certain states: adults in some states experience levels of disability one, or even two, decades before adults in other states.

Third, the variation in disability across states is similar for women and men. This is in contrast to mortality studies, which find that the geographic variation has historically been much greater for men (Ezzati et al., 2008; Wilmoth et al., 2011). There are at least two explanations for the discrepancy. One is the earlier time period (1980-2000) covered by mortality studies. Given that the variation in mortality grew much more among women than men during that time, the gender difference in mortality variation may have diminished by 2010 . Another potential explanation is that contextual determinants of disability may be more gender-neutral than the contextual determinants of mortality. In fact, our multilevel analyses provide some suggestive evidence for this: it found few gender differences in the both the type and magnitude of statelevel contextual factors that seem to matter for disability. In contrast, the type of state-level contextual factors that seem to matter for adult mortality differ between women and men, with states' socioeconomic context and social capital mattering more for women and states' tobacco environment mattering more for men (Montez et al., 2016). 
A fourth finding is that adult disability status is shaped by both state of residence and state of birth, corroborating prior studies (Kington et al., 1998; Lin, 2000; Lin \& Zimmer, 2002). By extension it seems likely that disability status is shaped by all state contexts an individual has been meaningfully exposed to; however, we are unable to empirically test this. Nonetheless, our finding underscores the importance of taking geographic context into account when examining social determinants of disability. The fact that an individual's state of birth can leave an enduring imprint on their disability status, net of their "fundamental" socio-demographic characteristics, for almost 90 years is a powerful message that context matters. Our findings also have datarelated implications. Because many publicly-available, national datasets for examining U.S. health and mortality do not provide state or local area of residence or birth, research on the social determinants of health is hindered by not being able to take these exposures into account. Furthermore, when these datasets do provide geographic identifiers they generally only provide current residence, which we find significantly underestimates geographic disparities in disability.

Fifth, living in a state with a strong economic output (measured by GSPPC) and a population that shares more equally in those fortunes seems to be particularly salubrious. One implication is that states' investments in their populations through policies and strategies that encourage economic growth and reduce income inequality may lower disability prevalence; however, studies designed to test causality are needed to confirm this. Another example of a state investment that may be especially salubrious is EITC. Living in states with a long history of offering an EITC appears to lower the odds of disability for women and men in later life. Given that few adults are in the labor force at these ages, this suggests that any disability-related benefits of EITC accrue over the life course and manifest most prominently after decades of exposure. Moreover, it is likely that the benefits of living in a state with EITC are not limited to EITC recipients. To the extent that EITC increases employment, raises incomes, reduces risky 
behaviors, and improves health as studies suggest, the benefits may reverberate across family members, friends, communities, and state budgets. We also found that higher tobacco taxes were associated with lower odds of disability among middle-age women. This makes sense given that women are twice as responsive as men to increases in cigarette prices (Stehr, 2007). It is unclear why the effect is limited to middle-age women. It may reflect the confluence of older smokers being the least price sensitive (Franz, 2008) and younger cohorts being the least likely to smoke.

Even though some state contexts were stronger predictors of women's than men's odds of disability, gender differences in the importance of state contexts were generally unimpressive. However, we did find some age differences in the importance of state contexts for adult disability. The contexts we examined accounted for about $2 / 3$ of the variation in middle-age and older adult disability across states compared to just $1 / 4$ for younger adults. While this makes sense in that middle-age and older adults have had longer exposure to their state of residence, the importance of state contexts for specific ages may be more nuanced than that. Indeed, our supplementary analyses, which ranked the states by their disability prevalence within 10-year age groups, showed that a few states manage to have low disability across most age groups and a few have high disability across most age groups, but the majority do well for some age groups and not others. Additional studies are needed to further tease out these age-specific patterns.

\section{Limitations}

Although the ACS is best data source to address our aims, it has some limitations. First, it does not provide detailed migration histories, which could provide more precise estimates of state exposures. Second, the cross-sectional nature of the data precludes distinguishing cohort and age effects or examining trends. Third, the ACS does not collect data on health behaviors or life course histories of respondents (e.g., employment histories). This information could be helpful 
for disentangling the myriad causal pathways linking state contexts and individuals' disability status. Ultimately, the structural measures that we examined shape disability status through more proximal pathways such as health behaviors, psychosocial stressors, and access to assistive devices.

It is important to bear in mind that while our state-level measures span five categories in the WHO framework, our measures are not intended to wholly capture each category. One implication is that the lack of association between a measure (e.g., Medicaid generosity) and adult disability does not imply that the category that it represents (e.g., health care system) is unimportant. It only implies that this measure of Medicaid was not important. It is also important to bear in mind that the importance of any measure should be interpreted cautiously because they often cluster with other observed, and unobserved, measures.

Despite these limitations, our study provides a conceptual foundation that future studies can build upon to evaluate additional state contexts. For instance, it may be informative to examine state-level political characteristics such as legislative ideologies. In addition, future studies may also want to examine whether certain contexts are especially important for other subgroups, such as socioeconomically-disadvantaged adults.

\section{Conclusion}

The prevalence of adult disability varies markedly across states, partly reflecting differences in states' policies and strategies. In particular, states with strong economic output and a population that shares more equally in those fortunes seem to be salubrious. The findings underscore the importance of assessing and addressing the socio-ecological determinants of adult disability. 


\section{REFERENCES}

CDC. n.d. State Tobacco Activities Tracking and Evaluation (STATE) System http://www.cdc.gov/statesystem/ (accessed 04.01.16).

Chetty, R., Stepner, M., Abraham, S., Lin, S., Scuderi, B., Turner, N., Bergeron, A., Cutler, D., 2016. The association between income and life expectancy in the United States, 20012014. JAMA, 315, 1750-1766.

Diderichsen, F., Evans, T., Whitehead, M., 2001. The social basis of disparities in health. In Evans, T., Whitehead, M., Diderichsen, F., Bhuiya, A., Wirth, M. (Eds.), Challenging Inequities in Health: From Ethics to Action. New York: Oxford University Press.

Erdman, K., Wolfe, S.M., 1987. Poor Health Care for Poor Americans: A Ranking of State Medicaid Programs. Washington DC: Public Citizen Health Research Group.

Evans, W.N., Garthwaite, C.L., 2014. Giving mom a break: the impact of higher EITC payments on maternal health. American Economic Journal: Economic Policy, 6, 258-290.

Ezzati, M., Friedman, A.B., Kulkarni, S.C., Murray, C.J.L., 2008. The reversal of fortunes: trends in county mortality and cross-county mortality disparities in the United States. PLoS Medicine, 5, 0557-0568.

Farrelly, M.C., Bray, J.W., Pechacek, T., Woollery, T., 2001. Response by adults to increases in cigarette prices by sociodemographic characteristics. Southern Econ. J., 68, 156-165.

Franz, G.A., 2008. Price effects on the smoking behaviour of adult age groups. Public Health, $122,1343-1348$.

Freedman, V.A., Kasper, J., Spillman, B., Agree, E., Mor, V., Wallace, R., Wolf, D.A., 2014. Behavioral adaptation and late-life disability: a new spectrum for assessing public health impacts. Am. J. Public Health Nations Health, 104, e88-94. 
Fuller-Thomson, E., Gadalla, T., 2008. Income inequality and limitations in activities of daily living: a multilevel analysis of the 2003 American Community Survey. Public Health, $122,221-228$.

Gadalla, T.M., Fuller-Thomson, E., 2008. Examining the lag time between state-level income inequality and individual disabilitie: a multilevel analysis. Am. J. Public Health, 98, 2187-2190.

Kachan, D., Tannenbaum, S.L., Olano, H.A., LeBlanc, W.G., McClure, L.A., Lee, D.J., 2014. Geographical variation in health-related quality of life among older US adults, 19972010. Preventing Chronic Disease, 11, 140023.

Kaiser Family Foundation. 2013. What is Medicaid's Impact on Access to Care, Health Outcomes, and Quality of Care?: http://kff.org/medicaid/issue-brief/what-is-medicaidsimpact-on-access-to-care-health-outcomes-and-quality-of-care-setting-the-recordstraight-on-the-evidence/ (accessed 04.15.16).

Kaiser Family Foundation. 2015. Medicaid Moving Forward. http://kff.org/health-reform/issuebrief/medicaid-moving-forward/ (accessed 04.15.16).

Kawachi, I., Kennedy, B.P., 1999. Income inequality and health: pathways and mechanisms. Health Serv. Res., 34, 215-227.

Kawachi, I., Kennedy, B.P., Lochner, K., Prothro-Stith, D., 1997. Social capital, income inequality, and mortality. Am. J. Public Health, 87, 1491-1498.

Kington, R., Carlisle, D., McCaffrey, D., Myers, H., Allen, W., 1998. Racial differences in functional status among elderly U.S. migrants from the South. Soc. Sci. Med., 47, 831840.

Leckie, G., 2013. Three-Level Multilevel Models - Stata Practical. LEMMA VLE Module 11, 152. http://www.bristol.ac.uk/cmm/learning/course.html (accessed 03.20.2016). 
Lin, G., 2000. Regional assessment of elderly disability in the U.S. Soc. Sci. Med., 50, 10151024.

Lin, G., Zimmer, Z., 2002. A geographic analysis of spatial differentials in mobility and self-care limitations among older Americans. International Journal of Population Geography, 8, 395-2002.

Mirowsky, J., Ross, C.E., 2003. Education, Social Status, and Health. New York: Aldine de Gruyter.

Montez, J.K., Hayward, M.D., 2011. Early life conditions and later life mortality. In Rogers, R.G., Crimmins, E.M. (Eds.), International Handbook of Adult Mortality. New York: Springer Publishers.

Montez, J.K., Zajacova, A., Hayward, M.D., 2016. Explaining inequalites in women's mortaltiy across U.S. states. SSM - Population Health, 2, 561-571.

National Research Council. 2011. Explaining divergent levels of longevity in high-income countries. Washington D.C.: The National Academies Press.

Navarro, V. (Ed.) 2004. The political and social contexts of health. Amityville, NY: Baywood Publishing Company, Inc.

Noss, A., 2011. Household Income for States: 2009 and 2010. U.S. Census Bureau. https://www.census.gov/prod/2011pubs/acsbr10-02.pdf (accessed 03.18.16).

Patel, S.A., Narayan, K.M.V., Ali, M.K., Mehta, N.K., 2014. Interstate variation in modifiable risk factors and cadiovascular mortality in the United States. PLoS ONE, 9, e101531.

Phelan, J.C., Link, B.G., 2005. Controlling disease and creating disparities: a fundamental cause perspective. Journal of Gerontolology: Social Sciences, 60(Spec), 27-33. 
Philibert, M., Pampalon, R., Daniel, M., 2015. Conceptual and operational considerations in identifying socioenvironmental factors associated with disability among communitydwelling adults. Int. J. Env. Res. Public Health, 12, 3814-3834.

Porrell, F.W., Miltiades, H.B., 2002. Regional differences in functional status among the aged. Soc. Sci. Med., 54, 1181-1198.

Ramírez de Arellano, A.B., Wolfe, S.M., 2007. Unsettling Scores: A Ranking of State Medicaid Programs. Washington DC: Public Citizen Health Research Group.

Solar, O., Irwin, A., 2010. A Conceptual Framework for Action on the Social Determinants of Health. Social Determinants of Health Discussion Paper 2 (Policy and Practice). Geneva: World Health Organization.

Stehr, M., 2007. The effect of cigarette taxes on smoking among men and women. Health Econ., $16,1333-1343$.

Strully, K.W., Rehkopf, D.H., Xuan, Z., 2010. Effects of prenatal poverty on infant health. State Earned Income Tax Credits and birth weight. Am. Sociol. Rev., 75, 534-562.

Stuck, A.E., Walthert, J.M., Nikolaus, T., Büla, C., Hohmann, C., Beck, J.C., 1999. Risk factors for functional status decline in community-living elderly people: a systematic literature review. Soc. Sci. Med., 48, 445-469.

Subramanian, S.V., Kawachi, I., Kennedy, B.P., 2001. Does the state you live in make a difference? Multilevel analysis of self-rated health in the US. Soc. Sci. Med., 53, 9-19.

TCWF. n.d. Tax Credits for Workers and Their Families. http://www.taxcreditsforworkingfamilies.org/ (accessed 03.20.2016).

Tencza, C., Stokes, A., Preston, S., 2014. Factors responsible for mortality variation in the United States: a latent variable analysis. Demographic Research, 31, 27-70. 
U.S. Bureau of Economic Analysis. n.d. http://www.bea.gov/iTable/index_regional.cfm (accessed 03.19.16).

U.S. Census Bureau. n.d. Income. Table S4. Gini Ratios by State: 1969, 1979, 1989, 1999. http://www.census.gov/data/tables/time-series/dec/historical-income-states.html (accessed 03.17.16).

Verbrugge, L.M., Jette, A.M., 1994. The disablement process. Soc. Sci. Med., 38, 1-14.

WHO. 2010. Gender, Women, and the Tobacco Epidemic. In Samet, J.M., Yoon, S.-Y. (Eds.). Geneva: WHO Press.

Wilmoth, J.R., Boe, C., Barbieri, M., 2011. Geographic differences in life expectancy at age 50 in the United States compared with other high-income countries. In Crimmins, E.M., Preston, S.H., Cohen, B. (Eds.), International Differences in Mortality at Older Ages: Dimensions and Sources pp. 333-366). Washington DC: The National Academies Press. 


\section{FIGURE CAPTION}

Figure 1. Age-Standardized Disability Prevalence for Adults Aged 24-94 Years and Born in Their State of Residence Notes: Data from the 2010-2014 American Community Survey. Age standardized to the 2010 U.S. Population. 
Table 1. Five Socioeconomic and Policy Characteristics of States, Spanning 1990 to 2010

\begin{tabular}{|c|c|c|c|c|c|}
\hline State & $\begin{array}{c}\text { Gross State Product } \\
\text { Per Capita }(\$)\end{array}$ & $\begin{array}{c}\text { Number of Years } \\
\text { State EITC }{ }^{a} \text { Available }\end{array}$ & $\begin{array}{l}\text { Gini Coefficient of } \\
\text { Income Inequality }\end{array}$ & $\begin{array}{c}\text { Sales Tax on Pack of } \\
\text { Cigarettes }(\$)\end{array}$ & $\begin{array}{c}\text { Medicaid } \\
\text { Program Score }\end{array}$ \\
\hline ND & 39360 & 0 & 0.424 & 0.440 & 316.6 \\
\hline $\mathrm{MN}$ & 47077 & 19 & 0.428 & 0.730 & 427.6 \\
\hline $\mathrm{HI}$ & 45688 & 0 & 0.425 & 1.400 & 382.6 \\
\hline WI & 41632 & 21 & 0.415 & 1.183 & 433.9 \\
\hline NJ & 52856 & 10 & 0.452 & 1.300 & 322.9 \\
\hline$\ldots$ & $\ldots$ & $\ldots$ & $\ldots$ & $\ldots$ & $\ldots$ \\
\hline $\mathrm{AL}$ & 33782 & 0 & 0.468 & 0.252 & 267.2 \\
\hline AR & 32693 & 0 & 0.455 & 0.593 & 287.9 \\
\hline KY & 36187 & 0 & 0.463 & 0.220 & 346.3 \\
\hline MS & 29714 & 0 & 0.474 & 0.347 & 225.4 \\
\hline WV & 32454 & 0 & 0.459 & 0.297 & 333.2 \\
\hline Average & 42775 & 5.2 & 0.442 & 0.683 & 335.1 \\
\hline Standard deviation & 7611 & 7.6 & 0.020 & 0.398 & 54.8 \\
\hline Minimum & 29714 & 0 & 0.407 & 0.070 & 225.4 \\
\hline Maximum & 62879 & 24 & 0.488 & 1.593 & 449.5 \\
\hline
\end{tabular}

Notes: Table sorted from lowest to highest age-standardized disability prevalence among adults born in their state of residence. This is the same sort order as Table 2. For parsimony only the 5 lowest and 5 highest states are shown. See appendix Table S2 for all 50 states.

${ }^{\mathrm{a}}$ EITC = Earned Income Tax Credit. Data are the number of years the state had offered an EITC prior to 2010. 
Table 2. Age-Standardized and Age-Specific Disability Prevalence among U.S. Adults Aged 25-94 Years by State, 2010-2014

\begin{tabular}{|c|c|c|c|c|c|c|c|c|c|c|c|c|}
\hline \multirow[b]{3}{*}{ State } & \multirow{3}{*}{$\begin{array}{l}\text { All Adults } \\
\text { ASDP }^{1}\end{array}$} & \multirow{3}{*}{$\begin{array}{l}\text { US-born } \\
\text { ASDP }\end{array}$} & \multicolumn{10}{|c|}{ Born in State of Residence } \\
\hline & & & & & & Ages $^{3}$ & Ages & Ages & Ages & Ages & Ages & Ages \\
\hline & & & ASDP & Diff $^{2}$ & $\mathrm{~N}$ & $25-34$ & $35-44$ & $45-54$ & $55-64$ & $65-74$ & $75-84$ & $85-94$ \\
\hline ND & 13.2 & 13.2 & 12.9 & -0.3 & 17,392 & 4.1 & 5.5 & 9.6 & 14.8 & 22.0 & 41.5 & 74.7 \\
\hline $\mathrm{MN}$ & 13.0 & 13.1 & 12.9 & -0.2 & 133,219 & 5.5 & 6.4 & 9.6 & 14.6 & 20.7 & 38.6 & 68.8 \\
\hline $\mathrm{HI}$ & 12.7 & 13.4 & 13.5 & 0.1 & 24,450 & 5.2 & 5.6 & 11.7 & 14.8 & 22.3 & 40.5 & 70.9 \\
\hline WI & 14.1 & 14.2 & 13.8 & -0.4 & 146,416 & 6.6 & 7.5 & 10.4 & 15.3 & 21.8 & 38.5 & 69.6 \\
\hline NJ & 12.6 & 13.6 & 13.9 & 0.3 & 134,793 & 5.8 & 7.0 & 11.0 & 15.9 & 22.0 & 40.4 & 70.5 \\
\hline IA & 14.2 & 14.5 & 14.1 & -0.4 & 79,841 & 5.9 & 7.3 & 11.2 & 16.5 & 22.6 & 39.7 & 67.4 \\
\hline $\mathrm{CT}$ & 13.1 & 13.7 & 14.2 & 0.5 & 60,203 & 6.5 & 7.9 & 11.1 & 15.3 & 22.6 & 41.1 & 65.2 \\
\hline $\mathrm{NE}$ & 14.3 & 14.5 & 14.4 & -0.1 & 41,906 & 5.3 & 7.6 & 11.1 & 15.7 & 25.0 & 42.5 & 71.7 \\
\hline NY & 13.8 & 14.8 & 14.7 & -0.1 & 403,608 & 6.2 & 8.2 & 12.2 & 16.9 & 22.6 & 40.2 & 68.5 \\
\hline UT & 14.4 & 14.9 & 14.8 & -0.1 & 46,464 & 5.9 & 7.2 & 11.4 & 18.4 & 25.1 & 40.6 & 72.2 \\
\hline IL & 14.0 & 14.8 & 14.8 & 0.0 & 277,471 & 5.6 & 7.7 & 11.8 & 17.5 & 24.5 & 41.8 & 70.9 \\
\hline MA & 13.9 & 14.4 & 14.9 & 0.5 & 134,842 & 7.0 & 8.2 & 11.8 & 16.2 & 22.7 & 41.8 & 71.2 \\
\hline $\mathrm{SD}$ & 15.1 & 15.2 & 15.0 & -0.2 & 18,521 & 6.4 & 7.8 & 11.4 & 17.2 & 24.3 & 44.5 & 71.4 \\
\hline$C A$ & 14.0 & 15.2 & 15.6 & 0.4 & 481,838 & 6.0 & 8.5 & 13.3 & 18.6 & 25.0 & 42.6 & 68.6 \\
\hline PA & 15.9 & 16.2 & 16.0 & -0.2 & 338,139 & 7.5 & 9.3 & 13.7 & 18.0 & 24.3 & 41.9 & 71.4 \\
\hline $\mathrm{NH}$ & 14.1 & 14.5 & 16.0 & 1.5 & 16,432 & 7.1 & 8.7 & 12.2 & 16.9 & 26.5 & 47.6 & 76.2 \\
\hline WY & 15.7 & 15.9 & 16.2 & 0.3 & 6,876 & 7.6 & 8.5 & 12.1 & 19.3 & 26.9 & 43.1 & 79.2 \\
\hline KS & 16.0 & 16.4 & 16.3 & -0.1 & 56,006 & 7.4 & 8.8 & 14.0 & 18.7 & 25.7 & 43.4 & 72.9 \\
\hline $\mathrm{RI}$ & 15.5 & 15.9 & 16.4 & 0.5 & 19,974 & 7.9 & 8.7 & 13.2 & 21.2 & 24.1 & 43.4 & 70.0 \\
\hline $\mathrm{MD}$ & 13.5 & 14.4 & 16.4 & 2.0 & 78,481 & 7.0 & 9.2 & 14.4 & 19.8 & 25.7 & 41.5 & 72.5 \\
\hline $\mathrm{DE}$ & 15.1 & 15.8 & 16.5 & 0.7 & 11,116 & 8.0 & 9.5 & 13.3 & 18.8 & 24.2 & 44.2 & 74.3 \\
\hline MT & 15.9 & 16.1 & 16.6 & 0.5 & 17,536 & 7.2 & 9.5 & 12.8 & 18.7 & 27.0 & 47.9 & 70.5 \\
\hline $\mathrm{CO}$ & 14.3 & 14.6 & 16.8 & 2.2 & 55,299 & 6.8 & 9.2 & 13.6 & 20.0 & 27.7 & 46.4 & 73.9 \\
\hline $\mathrm{OH}$ & 16.9 & 17.2 & 17.2 & 0.0 & 292,436 & 7.7 & 10.3 & 15.1 & 20.1 & 26.2 & 43.3 & 70.2 \\
\hline VT & 15.8 & 16.1 & 17.3 & 1.2 & 10,531 & 8.5 & 8.6 & 14.7 & 19.9 & 26.0 & 46.8 & 80.5 \\
\hline $\mathrm{Ml}$ & 17.0 & 17.5 & 17.4 & -0.1 & 257,261 & 8.4 & 10.3 & 15.0 & 20.6 & 26.4 & 43.4 & 69.9 \\
\hline WA & 15.9 & 16.8 & 17.4 & 0.6 & 91,371 & 8.4 & 10.5 & 15.0 & 19.8 & 26.7 & 44.0 & 70.5 \\
\hline ID & 16.7 & 17.1 & 17.5 & 0.4 & 20,265 & 6.6 & 10.0 & 13.7 & 20.7 & 29.8 & 48.3 & 78.6 \\
\hline IN & 17.1 & 17.5 & 17.6 & 0.1 & 146,624 & 7.3 & 10.1 & 15.4 & 21.0 & 27.8 & 45.9 & 72.6 \\
\hline VA & 14.4 & 15.3 & 17.8 & 2.5 & 119,341 & 7.3 & 10.0 & 15.6 & 21.5 & 28.5 & 46.9 & 73.0 \\
\hline $\mathrm{FL}$ & 14.7 & 16.1 & 18.2 & 2.1 & 147,621 & 7.0 & 9.2 & 15.4 & 23.9 & 30.0 & 49.5 & 74.7 \\
\hline OR & 17.3 & 17.9 & 18.4 & 0.5 & 49,705 & 9.1 & 12.2 & 16.6 & 20.3 & 27.2 & 44.0 & 69.7 \\
\hline $\mathrm{MO}$ & 18.0 & 18.4 & 18.5 & 0.1 & 132,625 & 7.9 & 10.6 & 16.7 & 22.4 & 28.7 & 46.1 & 75.0 \\
\hline NV & 16.0 & 17.3 & 18.8 & 1.5 & 9,118 & 7.4 & 10.3 & 14.1 & 24.1 & 32.6 & 51.2 & 77.8 \\
\hline$A Z$ & 14.9 & 15.7 & 18.8 & 3.1 & 51,940 & 6.7 & 9.4 & 16.1 & 23.2 & 32.5 & 53.2 & 76.3 \\
\hline $\mathrm{TX}$ & 16.7 & 17.8 & 19.0 & 1.2 & 435,854 & 7.1 & 9.9 & 16.0 & 23.8 & 32.7 & 51.2 & 77.3 \\
\hline $\mathrm{ME}$ & 17.7 & 17.9 & 19.3 & 1.4 & 29,143 & 10.0 & 11.4 & 17.3 & 22.5 & 28.4 & 46.7 & 76.1 \\
\hline $\mathrm{NC}$ & 17.2 & 17.8 & 19.6 & 1.8 & 180,098 & 7.9 & 10.4 & 17.3 & 25.0 & 31.3 & 50.9 & 77.8 \\
\hline $\mathrm{GA}$ & 16.9 & 17.8 & 19.8 & 2.0 & 161,741 & 7.5 & 10.2 & 17.6 & 25.8 & 33.8 & 51.5 & 77.0 \\
\hline LA & 19.7 & 20.1 & 20.4 & 0.3 & 114,292 & 8.2 & 10.9 & 17.8 & 26.0 & 35.0 & 51.9 & 77.4 \\
\hline SC & 18.0 & 18.4 & 20.5 & 2.1 & 89,882 & 8.0 & 10.5 & 18.6 & 27.1 & 33.6 & 51.9 & 78.8 \\
\hline AK & 16.7 & 17.1 & 21.1 & 4.0 & 8,006 & 5.9 & 7.9 & 15.9 & 25.0 & 44.0 & 75.4 & 74.4 \\
\hline $\mathrm{TN}$ & 19.6 & 20.1 & 21.3 & 1.2 & 126,380 & 8.9 & 12.3 & 19.8 & 27.1 & 33.4 & 50.7 & 78.5 \\
\hline OK & 20.4 & 21.0 & 21.3 & 0.3 & 71,436 & 9.2 & 11.9 & 18.9 & 27.4 & 35.2 & 52.1 & 75.6 \\
\hline NM & 18.6 & 19.3 & 21.4 & 2.1 & 30,508 & 9.4 & 12.5 & 17.2 & 26.4 & 35.1 & 57.7 & 76.6 \\
\hline $\mathrm{AL}$ & 20.6 & 21.0 & 21.9 & 0.9 & 113,119 & 8.8 & 12.8 & 19.9 & 28.9 & 34.2 & 53.1 & 79.2 \\
\hline$A R$ & 21.1 & 21.6 & 22.2 & 0.6 & 59,304 & 9.3 & 13.1 & 19.8 & 28.8 & 36.0 & 54.0 & 77.1 \\
\hline $\mathrm{KY}$ & 21.7 & 22.0 & 22.6 & 0.6 & 105,547 & 10.1 & 13.3 & 21.0 & 28.6 & 35.2 & 53.1 & 78.3 \\
\hline MS & 21.9 & 22.2 & 23.0 & 0.8 & 69,291 & 9.6 & 12.1 & 21.0 & 30.5 & 39.2 & 55.8 & 79.1 \\
\hline WV & 22.6 & 22.8 & 23.5 & 0.7 & 46,813 & 10.5 & 14.3 & 22.3 & 31.0 & 36.4 & 52.2 & 77.5 \\
\hline US & 15.7 & 16.6 & 17.3 & 1.6 & $5,571,075$ & 7.1 & 9.5 & 14.7 & 20.9 & 27.9 & 45.5 & 72.6 \\
\hline
\end{tabular}

Notes: Table sorted from lowest to highest ASDP for adults born in state of residence. All estimates are weighted.

${ }^{1}$ ASDP = age-standardized disability prevalence. It is standardized to the 2010 US population.

2 "Diff" is the difference in ASDP between adults born in their state of residence and all US-born adults.

${ }^{3}$ Cell shades reflect prevalence categories: $[0,10) \%$ lightest grey, $[10,20) \%$ light grey, $[20,30) \%$ grey, ..., 50+\% black. 
Table 3. Summary of Age-Standardized Disability Prevalence by Gender and Exposure to U.S. State, 2010-2014

Summary Statistics for the 50 States

\begin{tabular}{|c|c|c|c|c|c|c|}
\hline Categories of Exposure to U.S. State ${ }^{a}$ & Min & Max & Range & $I R^{b}$ & $\sigma^{c}$ & $\begin{array}{r}\text { Test for equality of } \sigma^{2} \\
\text { between categories }\end{array}$ \\
\hline Women & & & & & & $p=0.346^{d}$ \\
\hline State of residence (stayers) & 11.3 & 22.5 & 11.2 & 4.4 & 2.83 & ----- \\
\hline State of residence (stayers and in-migrants) & 11.9 & 22.1 & 10.2 & 3.1 & 2.53 & $p=0.224^{\mathrm{e}}$ \\
\hline State of residence (in-migrants) & 12.5 & 20.9 & 8.4 & 2.8 & 2.23 & $p=0.050^{\mathrm{e}}$ \\
\hline State of birth (stayers and out-migrants) & 11.6 & 21.7 & 10.1 & 3.8 & 2.52 & $p=0.213^{\mathrm{e}}$ \\
\hline State of birth (out-migrants) & 11.8 & 20.9 & 9.1 & 3.5 & 2.21 & $p=0.045^{\mathrm{e}}$ \\
\hline Men & & & & & & $p=0.086^{\mathrm{d}}$ \\
\hline State of residence (stayers) & 13.9 & 24.5 & 10.6 & 4.4 & 2.91 & ----- \\
\hline State of residence (stayers and in-migrants) & 13.4 & 23.6 & 10.2 & 3.3 & 2.56 & $p=0.188^{\mathrm{e}}$ \\
\hline State of residence (in-migrants) & 12.2 & 21.2 & 9.0 & 2.9 & 2.27 & $p=0.044^{\mathrm{e}}$ \\
\hline State of birth (stayers and out-migrants) & 13.6 & 21.9 & 8.3 & 3.9 & 2.39 & $p=0.085^{\mathrm{e}}$ \\
\hline State of birth (out-migrants) & 12.6 & 20.2 & 7.6 & 3.1 & 1.90 & $p=0.002^{\mathrm{e}}$ \\
\hline
\end{tabular}

Notes: all estimates are based on the age-standardized disability prevalence of U.S.-born adults within each state.

${ }^{a}$ Some categories overlap. For instance, "state of residence (stayers and in-migrants)" includes all adults residing in a state at the time of survey regardless of state of birth, while "state of residence (stayers)" includes the subset who were born in that state. The category "state of residence (stayers)" is the main category used in our study. "State of residence (stayers and in-migrants)" includes adults by state of residence regardless of state of birth. "State of residence (in-migrants)" includes adults by state of residence, among individuals not born in the state. "State of birth (stayers and out-migrants)" includes adults by state of birth, regardless of whether they migrated. "State of birth (out-migrants)" includes adults by state of birth, among individuals who migrated out of the state.

${ }^{b}$ IQR is the interquartile range, or the difference between the $75^{\text {th }}$ and $25^{\text {th }}$ percentile, of ASDP across states.

${ }^{c} \sigma$ is the standard deviation of ASDP across the 50 states.

${ }^{\mathrm{d}}$ Two-sided Brown-Forsythe test for equality of variances among the five exposure groups.

"One-sided F-test for equality of variances between "state of residence (stayers)" and each exposure group, where $H_{0}: \sigma_{\text {state of residence (stayers) }}^{2}=\sigma_{\text {other exposure category, }}^{2} H_{A}: \sigma_{\text {state of residence (stayers) }}^{2}>\sigma_{\text {other exposure category }}^{2}$ 
Table 4. Odds Ratios for Having a Disability among Women by Age Group, 2012-2014

\begin{tabular}{|c|c|c|c|c|c|c|c|c|c|}
\hline \multirow{2}{*}{ Individuals } & \multicolumn{3}{|c|}{ Ages 25-44 } & \multicolumn{3}{|c|}{ Ages 45-64 Years } & \multicolumn{3}{|c|}{ Ages 65-94 Years } \\
\hline & & & & & & & & & \\
\hline Age & $1.04 * * *$ & $1.04 * * *$ & $1.04 * * *$ & $1.04 * * *$ & $1.04 * * *$ & $1.04 * * *$ & $1.11 * * *$ & $1.10 * * *$ & $1.10 * * *$ \\
\hline \multicolumn{10}{|l|}{ Race (non-Hispanic white) } \\
\hline Non-Hispanic black & $1.47 * * *$ & $1.25 * * *$ & $1.24 * * *$ & $1.80 * * *$ & $1.68 * * *$ & $1.68 * * *$ & $1.58 * * *$ & $1.47^{* * *}$ & $1.47^{* * *}$ \\
\hline Non-Hispanic other & $1.46 * * *$ & $1.38 * * *$ & $1.38 * * *$ & $2.05^{* * *}$ & $1.96 * * *$ & $1.96 * * *$ & $1.69 * * *$ & $1.55^{* * *}$ & $1.56^{* * *}$ \\
\hline Hispanic & $1.19 * * *$ & $0.90 * * *$ & $0.90 * * *$ & $1.40 * * *$ & $1.12 * * *$ & $1.12 * * *$ & $1.43^{* * *}$ & $1.10 * * *$ & $1.10^{* * *}$ \\
\hline Education & & $0.80 * * *$ & $0.80 * * *$ & & $0.83 * * *$ & $0.83 * * *$ & & $0.90 * * *$ & $0.90 * * *$ \\
\hline \multicolumn{10}{|l|}{ States } \\
\hline Gross state product per capita & & & $0.95^{*}$ & & & $0.94 * *$ & & & $0.97^{*}$ \\
\hline Gini coefficient of income inequality & & & $1.06^{*}$ & & & $1.10 * * *$ & & & $1.06 * * *$ \\
\hline Years with Earned Income Tax Credit & & & 1.03 & & & 1.01 & & & $0.96 *$ \\
\hline Cigarette taxes per pack & & & 1.00 & & & $0.96+$ & & & 0.98 \\
\hline Medicaid program score & & & 1.00 & & & 0.98 & & & 0.99 \\
\hline \multicolumn{10}{|l|}{ Random Effects } \\
\hline Local $^{\mathrm{a}}\left(\sigma_{u}^{2}\right)$ & 0.101 & 0.059 & 0.059 & 0.107 & 0.068 & 0.068 & 0.034 & 0.024 & 0.024 \\
\hline State $\left(\sigma_{v}^{2}\right)$ & 0.040 & 0.027 & 0.020 & 0.058 & 0.043 & 0.015 & 0.036 & 0.028 & 0.011 \\
\hline Likelihood Ratio Test $^{\mathrm{b}}$ & 2,903 & 1,388 & 1,235 & 9,099 & 5,279 & 3,683 & 4,040 & 2,703 & 1,223 \\
\hline Akaike Information Criterion & 326,038 & 308,662 & 308,659 & 634,659 & 612,043 & 612,016 & 553,908 & 546,116 & 546,096 \\
\hline $\mathrm{N}$ & 581,692 & 581,692 & 581,692 & 707,375 & 707,375 & 707,375 & 464,838 & 464,838 & 464,838 \\
\hline
\end{tabular}

$* * * \mathrm{p}<0.001 ; * * \mathrm{p}<0.01 ; * \mathrm{p}<0.05 ; \mathrm{p}<0.10$

Notes: Sample includes adults born in their state of residence. Odds ratios estimated from multilevel logistic regression models. All state variables are Z-scores.

${ }^{a}$ Local areas are Public Use Microdata Areas (PUMAs).

${ }^{\mathrm{b}}$ This $\chi^{2}$ statistic tests whether the multilevel model fits the data better than an individual-level model [critical $\left.\chi^{2}(\mathrm{df}=2, \alpha=0.05)=5.99\right]$. 
Table 5. Odds Ratios for Having a Disability among Men by Age Group, 2012-2014

\begin{tabular}{|c|c|c|c|c|c|c|c|c|c|}
\hline \multirow[b]{2}{*}{ Individuals } & \multicolumn{3}{|c|}{ Ages 25-44 } & \multicolumn{3}{|c|}{ Ages 45-64 Years } & \multicolumn{3}{|c|}{ Ages 65-94 Years } \\
\hline & & & & & & & & & \\
\hline Age & $1.02 * * *$ & $1.02 * * *$ & $1.02 * * *$ & $1.05^{* * *}$ & $1.05 * * *$ & $1.05^{* * *}$ & $1.08 * * *$ & $1.08 * * *$ & $1.08 * * *$ \\
\hline \multicolumn{10}{|l|}{ Race (non-Hispanic white) } \\
\hline Non-Hispanic black & $1.69 * * *$ & $1.38 * * *$ & $1.37 * * *$ & $1.72 * * *$ & $1.49 * * *$ & $1.49 * * *$ & $1.33^{* * *}$ & $1.14^{* * *}$ & $1.14 * * *$ \\
\hline Non-Hispanic other & $1.40 * * *$ & $1.33^{* * *}$ & $1.33^{* * *}$ & $1.85^{* * *}$ & $1.74^{* * *}$ & $1.74^{* * *}$ & $1.61 * * *$ & $1.48 * * *$ & $1.49 * * *$ \\
\hline Hispanic & $1.24 * * *$ & $0.96 *$ & $0.96 *$ & $1.37^{* * *}$ & $1.10 * * *$ & $1.10 * * *$ & $1.38 * * *$ & $1.08 * * *$ & $1.08 * * *$ \\
\hline Education & & $0.81^{* * *}$ & $0.81^{* * *}$ & & $0.83 * * *$ & $0.83^{* * *}$ & & $0.91^{* * *}$ & $0.91^{* * *}$ \\
\hline \multicolumn{10}{|l|}{ States } \\
\hline Gross state product per capita & & & $0.94 * *$ & & & $0.94 * *$ & & & $0.95^{*}$ \\
\hline Gini coefficient of income inequality & & & $1.04^{*}$ & & & $1.06 * *$ & & & 1.01 \\
\hline Years with Earned Income Tax Credit & & & 0.98 & & & 0.98 & & & $0.96+$ \\
\hline Cigarette taxes per pack & & & 0.99 & & & 0.98 & & & 0.98 \\
\hline Medicaid program score & & & 1.03 & & & 0.98 & & & 0.98 \\
\hline \multicolumn{10}{|l|}{ Random Effects } \\
\hline Local $^{\mathrm{a}}\left(\sigma_{u}^{2}\right)$ & 0.109 & 0.069 & 0.069 & 0.106 & 0.062 & 0.062 & 0.042 & 0.022 & 0.022 \\
\hline State $\left(\sigma_{v}^{2}\right)$ & 0.028 & 0.017 & 0.011 & 0.041 & 0.030 & 0.012 & 0.040 & 0.034 & 0.017 \\
\hline Likelihood Ratio Test $^{\mathrm{b}}$ & 3,683 & 1,946 & 1,761 & 8,597 & 4,655 & 3,389 & 3,430 & 2,118 & 1,073 \\
\hline Akaike Information Criterion & 361,981 & 344,628 & 344,621 & 631,322 & 605,478 & 605,465 & 450,775 & 443,355 & 443,345 \\
\hline $\mathrm{N}$ & 583,008 & 583,008 & 583,008 & 669,347 & 669,347 & 669,347 & 358,703 & 358,703 & 358,703 \\
\hline
\end{tabular}

$* * * p<0.001 ; * * p<0.01 ; * p<0.05 ;+p<0.10$

Notes: Sample includes adults born in their state of residence. Odds ratios estimated from multilevel logistic regression models. All state variables are Z-scores.

${ }^{\mathrm{a}}$ Local areas are Public Use Microdata Areas (PUMAs).

${ }^{\mathrm{b}}$ This $\chi^{2}$ statistic tests whether the multilevel model fits the data better than an individual-level model [critical $\left.\chi^{2}(\mathrm{df}=2, \alpha=0.05)=5.99\right]$. 


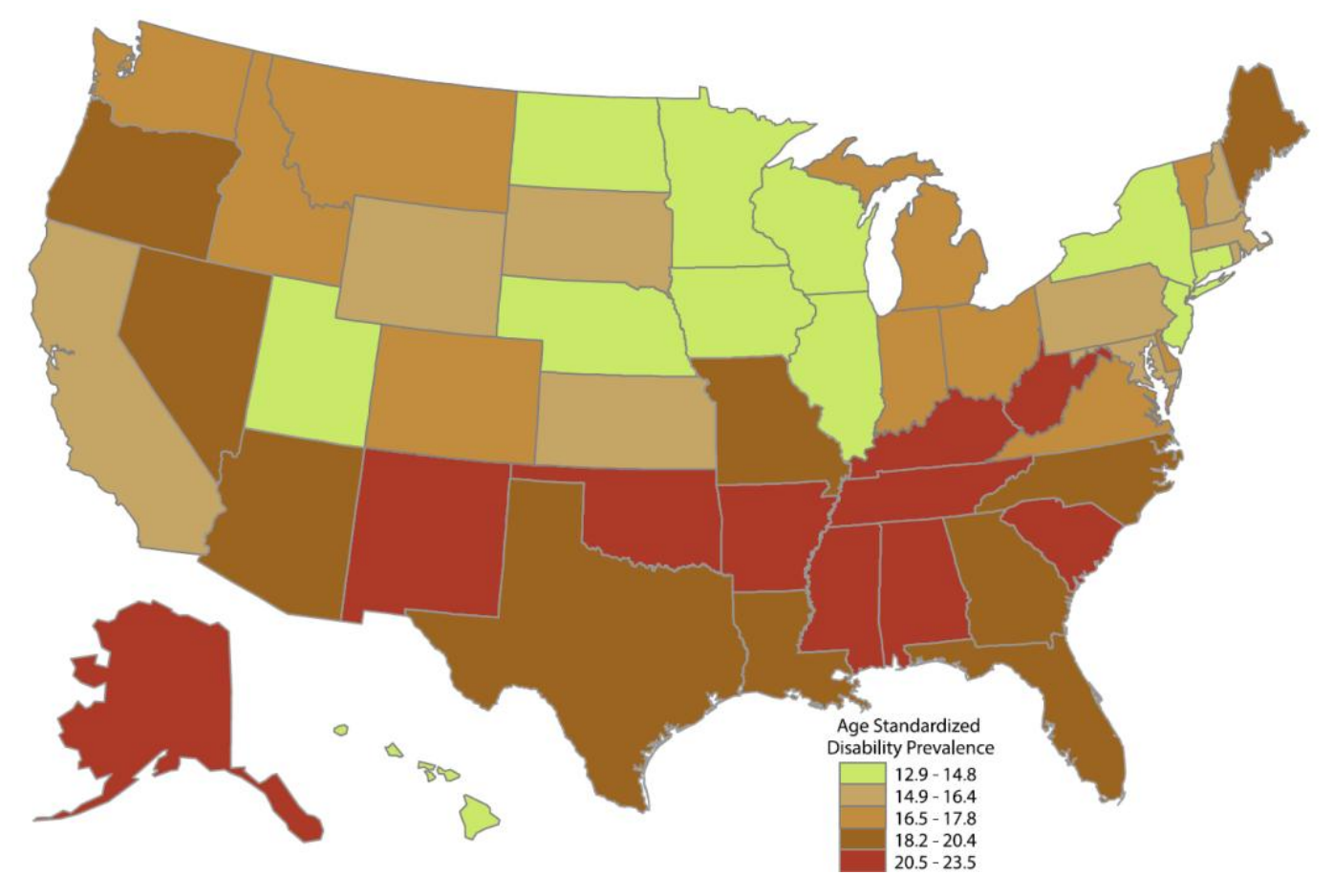

Figure 1. Age-Standardized Disability Prevalence for Adults Aged 24-94 Years and Born in Their State of Residence Notes: Data from the 2010-2014 American Community Survey. Age standardized to the 2010 U.S. Population. 